\author{
Proceedings of the Annual Scientific Meeting of the \\ International Medical Society of Paraplegia held at \\ Stoke Mandeville Hospital on 28th to 3oth July 197 I (Part II)
}

\title{
PSYCHOLOGICAL AND SOCIAL PROBLEMS OF PARAPLEGICS IN PAKISTAN
}

\author{
By Dr. Z. K. KazI and Asim QuRESHI \\ Paraplegia Research Project, Finnah Postgraduate Medical Centre, \\ Karachi (Pakistan)
}

THIS study is based on a vocational rehabilitation research project sponsored by Social and Rehabilitation Services, Department of Health, Education and Welfare, United States of America, and has been carried out in our Centre over a period of five years from I 966 to I97I. We have had the opportunity to study 200 cases of paraplegia. The aetiology ranged from trauma and tuberculosis of spine to spinal tumours and neurological degenerative diseases. The problems are discussed with regard to those who did not recover. It may be mentioned that about 85 per cent. of tuberculosis cases recovered after surgical decompression. Recovery rate of traumatic cases was low.

Initially we found that the permanent paraplegics, in the majority of cases, were from low socio-economic class. This means that they were low in educational standard and earning capacity, some completely illiterate, as education is not compulsory in Pakistan as yet. Many patients came from areas where not only schools were non-existant but it was not a social custom to educate the children. There is a combined family system and all members take part in farming or other work, right from childhood. This class of paraplegics has been found to be most difficult to rehabilitate economically and socially in their own society. (Their dialect may even be foreign to us in the city.)

The very small proportion who were initially educated were rehabilitated socially and economically with less difficulty. We can cite only three examples where education and socio-economic status have made it easy to rehabilitate these paraplegics. One with complete traumatic paraplegia has gone back to the government department where he works as a storekeeper in a wheelchair. He has been provided by the Government with a house near by where alterations have been carried out by our project. The other two are ladies who have been provided with all facilities in their houses by their relations for activities of daily living. They do not have to earn their living, but one of them does embroidery work and sells the items at fairs organised by the project.

We have, on our list, a few patients who were students before becoming paraplegics and are now continuing their studies in schools, colleges and universities.

Unfortunately the vast majority of our permanent paraplegics are from low socio-economic class, e.g. labourers, mill workers, farmers and shepherds, and some are totally unemployed. Their problems are two-fold in the first instance:

I. Those of living conditions at home; self-dependency or being helped out by their relations.

2. Earning a living for themselves and their families.

$\mathrm{H}$ 
In the first one the problems are:

(a) Housing. Only a little over 50 per cent. lived in what may be called regular houses. However, the accommodation ranged from one room to three rooms at the most for a family whose members ranged from four children and wife; and in some cases the wife's relatives or his own relatives and their families. There would be only one toilet and bathroom in any house. The houses do not have lifts. Almost all the houses are built above the ground with a plinth of 3-4 feet at least, requiring alterations for wheelchair mobility in form of ramps.

The rest, i.e. a little under 50 per cent. of the permanent paraplegics, did not have regular houses. They lived in huts temporarily erected with four walls and thatched roof at the place of their work. They are like nomads who shift from working place to working place. Those who come to cities from up-country and hills and deserts do not have houses at all but live in groups for a while and then after earning something go back home and come back when they have finished their money.

Those who go home after leaving the hospital live with their relations in hills and villages without medical help of any definite value. They come for readmission to hospital after their condition deteriorates enough for them not to be able to carry on at home.

It is obvious that adequate housing facilities with alteration in the home to facilitate activities of daily living are a must for these patients, and this is their primary problem. Only charitable agencies or a social agency can provide this or a national health scheme can do so. Patients themselves of the low economic class cannot obtain these conditions.

(b) Transport. To start with, city transport is always inadequate as it cannot keep pace with the growing population of a city or expansion of limits of the city. Even able-bodied persons are without cheap transport. Public transport is not prepared to accommodate paraplegics. The paraplegic, therefore, has to move in his wheelchair or with crutches, or he is carried from place to place by his relatives, who may take him in scooter rickshaw or taxi at a high cost. He, therefore, does not move out much and does not take his place amongst his social groups. In villages and hills there may be very little public transport.

Income. The problems concerned here are:

(i) Lack of insurance.

(ii) Low educational status.

(iii) Lack of legislation to employ disabled.

(iv) No disability allowance or pension.

Most of our patients were daily wage earners and casual workers who were not insured against accidents and permanent disability. There is hardly any system of individual insurance against accident in our country and non-existent among the independent labouring class. Those who work in factories and other employment agencies are to an extent insured against accident disability and unemployment. However, once a worker has become unfit to work he is given a very inadequate lump sum and discharged from service. Anyone with less than 20 per cent. disability may be employed again, but with more than 20 per cent. disability is not re-employed and, if re-employed, is not insurable. Paraplegics come under Ioo per cent. disability group. 
We have tried to solve these problems by taking into consideration the following:

These paraplegics who may be taught a profession which can be carried out in their homes, and for this purpose some paraplegics have shifted their homes to appropriate localities and live so close to their place of work that they can go there in a wheelchair or on crutches.

With this in view we have set out vocational rehabilitation programmes, teaching these patients such professions as tailoring, shopkeeping, typing, woodwork and carpet weaving. Following these professions, our patients have been able to earn anything from Rs $100 /-$ to Rs $300 /-$ per month which is just adequate for basic needs. Some patients are helped out by their family members who provide a further source of income. We have provided sewing machines, wheelchairs, crutches, braces and carried out alterations in their houses. We have also set up shops for them. Those who have to go out of the city are sent at our expense and we pay their expenses as well as of the relatives or friends who accompany them. In three cases our social worker has accompanied them to inaccessible hills.

\section{PSYCHOLOGICAL PROBLEMS}

Amongst our patients the psychological problems confronted are not different from those in other countries. However, social status, type of society and state of economic development produce their own problems vis-à-vis the paraplegics.

To start with, immediate acceptance of permanent disability is fought against by the patient. Nor do the treating staff have courage to tell the patient that he might not walk normally again. Slow breaking of the news is the method followed. One can discuss the advantages and disadvantages of the system.

Illiteracy, Language Barrier. Many patients coming to the hospital from far away speak their own dialect and without an interpreter it is difficult to communicate with them for immediate psychological assessment. There is no doubt that these patients learn the lingua franca, namely Urdu, very quickly, and then the psychologist can assess their mental make up. But other difficulties arise. The usual psychological tests are invented for the educated and literate and are standardised in other countries. They have to be altered and modified to suit our population. By the time assessment can be made by the psychologist, suggestion by other patients and staff of the ward, observation by the patient himself and attitude of the staff have already affected the type of result we would obtain. Correct assessment, therefore, is marred by these factors.

Motivation. Patients of the lower socio-economic group have strange traditional traits compared with the educated group. They may have complexes and usually want to follow the same profession as they have before the disability or which their ancestors have followed. In this group come farmers, who still want to work in farms and do not wish to set up a shop. A nomadic casual labourer wants his independence and does not want to learn tailoring. And yet our psychologist has been able to motivate fairly successfully these patients to take up occupations like tailoring, shopkeeping, etc.

Having motivated them mentally, physical motivation poses problems. Pain, disability and frustration take their toll. 


\section{HOSPITAL ADDICTION}

Hospital addiction may be attributed to two factors. The ease of life in hospital and sense of security and protection; also acceptance by the hospital staff and comraderie with other patients. Add to this all various difficulties at home, non-acceptance by wife or husband and relatives, lack of ease of life and care and insecurity. There is also loss of prestige due to incontinence of urine and faeces.

Even vocational rehabilitation is resisted by some as they feel that once they get rehabilitated they will be sent home with their residual disability, which again they are not prepared to accept.

As stated before, some patients find it against their dignity to take certain professions, especially shopkeeping. A farmer patient refused to do anything other than his father's profession of farmer. A waiter in a restaurant would not learn tailoring because he was a waiter and moved amongst the élite for 30 years.

Home Acceptance. The very poor patient is accepted by his or her spouse and children. In fact, even the relatives rally round him. The upper-class patient is also accepted likewise. But the lower middle class finds difficulties at home. Sex relations form a major part of the quarrel, but inability to provide amenities of life by the husband for the family also looms large. In some instances the wife has started earning and has demanded her independence. The husband then accuses her of infidelity.

However, by and large, the paraplegics are accepted in the family without much trouble. Motivation has been successful and the professions taught are being followed by a few people.

Finally, the social problems are those of getting to work, work opportunities, house acceptance and living conditions. There is no state economic support.

Psychological problems include acceptance by family and friends, personal dignity, resistance to motivation for activities of daily living and to vocational rehabilitation. 